\title{
Euskararen eta gaztelaniaren erabilera ingeleseko irakaskuntza-saioetan
}

\author{
Elizabet Arocena Egaña \\ Hizkuntzaren eta Literaturaren Didaktika \\ Hezkuntza, Filosofia eta Antropologia Fakultatea (UPV/EHU) \\ mirenelizabet.arocena@ehu.eus
}

DOI: http://dx.doi.org/10.1387/tantak.19825

GAKO-HITZAK: Kode-aldaketa, hezkuntza eleaniztuna, jardun eleaniztunak, EMI, bigarren hezkuntza.

\section{SARRERA}

Mundu osoan zeharreko hainbat ikerketak erakutsi dute testuinguru eleaniztunetan irakasle eta ikasleek beren $\mathrm{H} 1$ eta $\mathrm{H} 2$ erabiltzen dituztela atzerriko hizkuntzako eskola-orduetan (Levine, 2011; Littlewood \& Yu, 2011; Costa, 2011; Lin, 2015). Sarritan, code-switching edo kode-aldaketa gisa erabiltzen dira hizkuntzak, komunikatzeko eta besteekin harremanak izateko. Alabaina, beste hizkuntzen erabilera mugatua da oraindik atzerriko hizkuntzako irakaskuntza-saioetan, Cummins-ek $(2014,9$. or.) «monolingual instructional assumptions» deitzen dituen uste aski hedatuen eragina dela-eta. Elebakartasunean oinarritutako irizpideak honako hauek dira: (1) atzerriko hizkuntza soilik erabiltzea, (2) H1en eta atzerriko hizkuntzaren arteko itzulpenik ez egitea, eta (3) bi hizkuntzak zorrotz bereiztea.

Murgiltze-eskola elebakarren bidez ikasleak elebidun edo eleaniztun bihurtuko direlakoan H1en erabilera mugatu nahi izateak eragozten du ikaskuntza-prozesuan ikasleen $\mathrm{H} 1$ beste baliabide eraginkor bat izatea. Hizkuntzen bereizketa bai ingelesa ikasteko murgiltze-eskoletan bai ingelesa irakats-hizkuntza (EMI-English Medium Instruction) den eskoletan gertatzen da. Kanadan, frantseseko murgiltze-eskoletan $\mathrm{H} 1 \mathrm{ez}$ erabiltzea erabaki zen, hain zuzen, H2ren jabekuntza oztopa zezakeela iritzi zitzaiolako (Ballinger, 2015). EMI eskolek Europan, Asian eta Latinoamerikan duten arrakastaren gakoetako bat da zenbait herrialdetan ikasleek ingelesarekiko esposizio mugatua dutela eta hizkuntza hori erabiltzeko aukera 
murritza. Irakaskuntza-metodologia horrek ingelesa ikasteko hizkuntza horrekiko esposizio-denbora areagotzea sustatzen du. Printzipio hori oinarri harturik, EMI metodologiaren defendatzaileak $\mathrm{H} 1$ eta/edo $\mathrm{H} 2$ erabiltzearen aurkakoak dira, ikasleek ez dutelako xede-hizkuntzaren inputa jasotzen eta xede-hizkuntzaren outputa sortzera behartuta ez daudelako (Loewen, 2014).

Hizkuntzen bereizketa zurrunaren aldeko politikak duen babesaren eraginez, hezkuntzako eta eskoletako arduradun, irakasleen prestatzaile, argitaratzaile eta irakasle askok xede-hizkuntza ez den beste edozein baztertzen dute, jardunbide egokiena hori dela sinetsita. Ondorioz, irakasle askok nekez onartzen dute beren klaseetan code-switching edo kode-aldaketa baliatzen dutenik edo beste hizkuntzaren bat erabiltzen dutenik, praktikan hori egin arren (Lin, 2006).

\section{Kode-aldaketa ikasgela eleaniztunean}

Ikerketa-esparru honetan code-switching delakoaren ikuspegi desberdinak dauden eta askotariko definizioak eman diren arren, artikulu honetan code-switching edo kode-aldaketa esaten zaio «elebidunek (edo eleaniztunek) diskurtsoan bi hizkuntza edo gehiago nahasteari, sarritan solaskidea edo gaia aldatu gabe ere» (Poplack, 2001, 2062. or.). Hizkuntzen nahasketa egitura linguistikoaren edozein mailatan gerta daiteke, baina ikerketa honetan hizketaldi bakar batean gertatzen denaz arituko gara.

Ikertzaile ugarik aztertu dute H1en erabilera H2ko murgiltze-eskoletan. Ikerketa horiek irakasleen kode-aldaketari buruzkoak dira batez ere, eta askoz gutxiago aztertu da ikasleek nola nahasten dituzten hizkuntzak. Littlewood eta Yuk (2011) dioten moduan, ikasleen kode-aldaketa aztertzea ez da zeregin erraza, ahal bezain laster beren $\mathrm{H} 1$ erabiltzen dutelako eta, horrenbestez, zaila delako kode-aldaketa guztiak jasotzea. Ez dira gauza bera talde txikietan lan egitean gertatzen den kode-aldaketa eta ikasgela osoa elkarrekin lanean ari dela gertatzen dena. Beste ikerketa batzuek erakusten dute irakasle eta ikasleek oso gutxi edo batere ez dutela erabiltzen $\mathrm{H} 1$, eta ikasleek $\mathrm{H} 2 \mathrm{n}$ duten gaitasuna areagotu ahala gutxituz doala erabilera hori (Lo, 2015; MacMillan \& Turnbull, 2009).

Zenbait ikerketak (Swain \& Lapkin, 2000; Storch \& Aldosari, 2010, Ghorbani, 2011) ikasleen H1en erabilera eta funtzioak aztertu zituzten bikote/talde jardueretan. Swain eta Lapkin-ek (2000), frantseseko murgiltze-eskoletan H1en (ingelesa) erabilera aztertzen zuen ikerketa batean, ondorioztatu zuten ikasleek, irakasleek uste zutenaren kontra, H1 gutxi erabiltzen zutela bikotekako jardunean, eta batez ere lanean ari ez zirenean erabiltzen zutela. Gisa berean, Storch eta Aldosarik (2010) ere ondorioztatu zuten ikasleek gutxitan erabiltzen zutela $\mathrm{H} 1$ bikote/talde jardueretan, eta itxura batean jarduera-motak eragin handiagoa zuela H1en erabileran. 
Ikerketen arabera, ikasleek besteekin hitz egiteko eta elkarlanean jarduteko erabili ohi dute batez ere beren H1 (Swain \& Lapkin, 2000; Costa, 2011; Storch \& Aldosari, 2010).

Irakasleen hizkuntza-erabilera aztertzean, ikertzaileak ez dira ados jartzen atzerriko hizkuntzaren irakaskuntzan $\mathrm{H} 1$ erabili beharko litzatekeen, eta, erabili behar bada, nola. Littlewood eta Yuk (2011) adierazi moduan, atzerriko hizkuntzako eskola-orduetan H1 eta xede-hizkuntza erabiltzearen inguruko eztabaidak luze iraungo du, xede-hizkuntza ahalik eta gehien erabiltze aldera hizkuntzak bereizi behar direlako usteak sustrai sakonak baititu. Bigarren hizkuntzaren jabekuntzan H1 kode-aldaketa gisa erabiltzeko joera luze eta zabal aztertu da (Levine, 2011; Macaro, 2005, 2009; Swain \& Lapkin, 2000; Lewis, Jones \& Baker 2013; Lin, 2013), baina ez hainbeste CLIL (Content and Language Integrated Learning) edo EMI eskolen testuinguruan. CLIL eskoletako H1en erabilerari buruzko zenbait ikerketak (Gierlinger, 2015; Costa, 2011) agerian utzi dute kode-aldaketa oso baliagarria izan daitekeela baliabide pedagogiko eta/edo ikaskuntzaren bultzagarri gisa. Gierlingerrek (2015) iradoki duenez, ikerketa-eremu garrantzitsua izan liteke CLIL eskoletako irakasleen kode-aldaketari buruzko usteak eta erabilerak aztertzea, eskola horietako kode-aldaketaren ezaugarrietan aurkitu diren antzekotasunek aditzera ematen baitute baliabide hori ez dela akaso halabeharrez erabiltzen. Lasagabasterrek (2013), Kolonbian 35 CLIL irakaslegairekin egindako ikerketa batean, aurkitu zuen irakasleek kode-aldaketa erabiltzen zutela, hain zuzen, ikasleek bereziki zailak ziren gramatikaren zenbait alderdi eta ezagutzen ez zituzten hitzak ulertzen zituztela ziurtatzeko, eta orobat diziplina ezartzeko.

Alabaina, CLIL ikasgeletan kode-aldaketa eta jardun eleaniztunak sarritan ez dira abegi onez hartzen. Xede-hizkuntzarekiko hartu-eman handiagoa bermatzearen printzipioa oinarri harturik, EMI metodologiaren defendatzaileak $\mathrm{H} 1$ eta/edo $\mathrm{H} 2$ erabiltzearen aurka agertu ohi dira, ikasleek ez dutelako xede-hizkuntzaren inputa jasotzen eta maiz ez daudelako xedehizkuntzaren outputa aktiboki sortzera behartuta (Loewen, 2014).

Euskal Herrian, ikasgelan hizkuntzak nahastearen aurkako usteak sendoak dira oraindik irakasleen eta eskola-arduradunen artean. Ingeleseko ikasgelan xede-hizkuntza soilik erabiltzeko joeran eragin nabarmena dute irakasleek beren lanbide-ikastaroetan garatzen dituzten usteek, zeinek sarri askotan elebakartasuna izaten baitute oinarri (Arocena, Cenoz \& Gorter, 2015). Areago, kontuan hartuz euskal ikasleek ikasgelatik kanpo ingelesarekiko hartu-eman murritza eta hizkuntza hori erabiltzeko aukera gutxi dituztela, irakasleak nahiko zorrotzak izan ohi dira atzerriko hizkuntzako ikasgelan xede-hizkuntza soilik erabiltzearen inguruan (Arocena \& Popma, 2014). 


\section{Kode-aldaketaren funtzioak}

Zenbait egilek kategoriatan eta funtzioen arabera aztertu eta sailkatu dute H1en erabilera atzerriko hizkuntzaren ikasgelan. Ikerketa honetan - zeina doktore-tesi argitaragabe baten zatia baita-, alde batetik, Gierlingerrek (2015), Lok (2015) eta Littlewood eta Yuk (2011) identifikatutako funtzioak ikertu eta aztertu ditugu, hain zuzen ere, edukiak ingelesez irakasten ziren EMI eskoletan egin zituztelako beren ikerketak, eta, bestetik, Linek (2006) eta Lewis, Jones eta Bakerrek (2013) identifikatutakoak, beren kode-aldaketari buruzko ikerketak programa elebidunetan egin zituztelako.

Egile horiek identifikatutako kategorien eta funtzioen arteko antzekotasun eta desberdintasunei buruzko gure ikerketan oinarrituta, 1. taulan jasotako sailkapen-eskema sortu genuen (taularen lanketari eta iturriei buruzko zehaztasun gehiago nahi izanez gero, ikus doktore-tesi $\operatorname{argitaragabea}^{1}$ ).

1. taula

Kode-aldaketa arautzaile/hezitzailearen eskema

\begin{tabular}{c|l|l}
\hline Kategoria & \multicolumn{1}{|c|}{ Azpikategoria } & \multicolumn{1}{c}{ Funtzioa } \\
\hline \multirow{2}{*}{ Arautzailea } & $\begin{array}{l}\text { Jokabideen/ikasgelaren } \\
\text { kudeaketa }\end{array}$ & $\begin{array}{l}\text { Diziplina mantentzea, jakinarazpenak } \\
\text { egitea eta jarraibideak ematea. }\end{array}$ \\
\cline { 2 - 3 } Hezitzailea & Soziala eta afektiboa & $\begin{array}{l}\text { Hizkuntza-antsietatea murriztea, giro } \\
\text { goxo eta atseginagoa sortzea eta ikas- } \\
\text { leekin harreman ona garatzea. }\end{array}$ \\
\cline { 2 - 3 } & Lexikoaren transmisioa & $\begin{array}{l}\text { Hitzen itzulpen azkarra eta ikasgaiari } \\
\text { buruzko terminologiaren itzulpen para- } \\
\text { leloak. }\end{array}$ \\
\hline & Edukiaren transmisioa & $\begin{array}{l}\text { Kontzeptu zailen azalpenak eta dago- } \\
\text { kion gaia kontzeptualki ulertzen dela } \\
\text { ziurtatzeko itzulpenak. }\end{array}$ \\
\hline
\end{tabular}

1. taulan ageri denez, bi kategoria nagusiak kode-aldaketa arautzailea eta hezitzailea dira. Lehenengo kategorian, kode-aldaketa arautzailean, jokabideak eta ikasgela oro har kudeatzeko erabiltzen da, alde batetik, kode-aldaketa; hau da, H1 erabiltzen da diziplina ezartzeko, ikasgelari dagozkion jakinarazpenak egiteko eta jarraibideak emateko. Bestetik, ko-

1 Arocena, E. (2017). Multilingual Education; Teachers' Beliefs and Language Use in the Classroom. Doktore-tesi argitaragabea. Euskal Herriko Unibertsitatea, UPV/EHU. 
de-aldaketa sozial eta afektiboa ere sartzen da kategoria honetan. Kasu horretan, hizkuntza-antsietatea murrizteko, giro goxo eta atseginagoa sortzeko eta ikasleekin harreman ona garatzeko erabiltzen da H1. Oro har, H1 ikasgelan ikasteko ingurune egokia mantentzeko erabiltzean datza kode-aldaketa arautzailea.

Bigarren kategoria nagusia, kode-aldaketa hezitzailea, $\mathrm{H} 1$ helburu pedagogikoekin erabiltzean datza. Horrenbestez, H1 erabiltzen da, besteak beste, lexikoa transmititzeko, normalean hitzen itzulpen azkarrak edo ikasgaiari buruzko terminologiaren itzulpen paraleloak eginez. Kategoria honetan sartzen da, halaber, H1 erabiltzea edukia transmititzeko, kontzeptu zailen inguruko azalpenak emanez edo dagokion gaia kontzeptualki ulertzen dela ziurtatzeko itzulpenak eginez.

Bestalde, testuinguru eleaniztunetan hizkuntza-erabilera aztertzean kontuan izan beharko liratekeen kode-aldaketaren zenbait ezaugarri identifikatu ditugu. Ezaugarriok 2. taulan jaso ditugu.

2. taula

Kode-aldaketaren ezaugarriak

\begin{tabular}{|c|c|}
\hline Kategoria nagusia & Azpikategoria \\
\hline \multirow{2}{*}{ KA Ekoizlea } & Irakaslea \\
\hline & Ikaslea \\
\hline \multirow{3}{*}{ KA Hizkuntza } & $\mathrm{H} 1$ \\
\hline & $\mathrm{H} 2$ \\
\hline & $\mathrm{H} 1$ eta $\mathrm{H} 2$ \\
\hline \multirow{5}{*}{ KA Mota } & Bat-batekoa \\
\hline & Eskatutakoa \\
\hline & Nahita egindakoa \\
\hline & Jarraipenekoa \\
\hline & Xede-hizkuntzaren erabilera pedagogikoa etetekoa \\
\hline
\end{tabular}

2. taula honetan, gure testuinguru eleaniztunean esanguratsutzat jo ditugun kode-aldaketaren kategoriak eta ezaugarriak aurkeztu ditugu. Lehenengo ezaugarria ekoizlea da, hau da, nork ekoizten duen kode-aldaketa (irakasleak edo ikasleak/ek). Bigarren ezaugarria hizkuntza da: kode-aldaketan, xede-hizkuntzaz gain zer beste hizkuntza erabiltzen den $(\mathrm{H} 1, \mathrm{H} 2$ 
edo biak batera). Eta identifikatu dugun hirugarren ezaugarria kode-aldaketa mota da (bat-batekoa, eskatutakoa, nahita egindakoa, jarraipenekoa eta xede-hizkuntzaren erabilera pedagogikoa etetekoa).

\section{HELBURUA ETA IKERKETA-GALDERAK}

Ikerketa honen helburua da $\mathrm{H} 3$ (ingelesa) ikasgelan $\mathrm{H} 1$ (euskara) eta H2ren (gaztelania) erabilera identifikatu eta aztertzea, ikasgeletan hizkuntzen bereizketa oraindik arau nagusia den garaiotan. Helburu hori lortzeko, bi ikerketa-galdera hauek proposatu ditugu:

1. Zer ezaugarri eta funtzio dituzte atzerriko hizkuntzaren ikasgelan izaten diren kode-aldaketek?

2. Irakasleek beren hizkuntza-erabileraz duten pertzepzioa bat al dator haien eskoletan behatutako hizkuntza-erabilerarekin?

\section{METODOA}

Ikerketa hau hezkuntza eleaniztunari buruzko doktore-tesi baten parte da. Tesiaren izenburua honako hau da: (Blind reviewerako ezabatuta) Multilingual Education; Teachers' Beliefs and Language Use in the Classroom (Arocena, 2017).

\section{Testuingurua}

Euskal Herriko testuinguru eleaniztunak eleaniztasunaren eta hizkuntzen erabileraren fenomenoa aztertzeko aukera paregabea eskaintzen du. Ikerketa hau Euskal Herriko bi ikastolatan egin zen.

Oro har, hiru irakats-hizkuntzak - euskara, gaztelania eta ingelesabereizirik mantentzeko xedeari jarraituz antolatu da hizkuntzen irakaskuntza euskal ikastetxeetan. Alabaina, aurreko ikerketek erakusten dute praktikan kode-aldaketa izan badela hizkuntzen irakaskuntzan. Horrenbestez, gure helburua da atzerriko hizkuntza ikasteko prozesuan irakasle eta ikasleen kode-aldaketa aztertzea.

\section{Parte-hartzaileak}

Ikerketa kualitatibo eta kuantitatibo honen xedea zen kode-aldaketaren presentzia eta ezaugarriak aztertzea, ingelesa irakats-hizkuntza den Ingeleseko eta Historiako klaseetan. Horretarako, irakasle zein ikasleen hizkuntza-erabilera aztertu nahi genuen derrigorrezko bigarren hezkuntzako 
goiko mailetan. Antzeko ingurune sozioekonomiko eta soziolinguistikoa duten Euskal Herriko bi ikastetxetan (1 ikastetxea eta 2 ikastetxea) bildu genituen datuak.

Alde batetik, bigarren hezkuntzako bi ikastetxeetako irakasle banaren hizkuntza-erabilera aztertu genuen, eta, bestetik, bi ikastetxe horietan derrigorrezko bigarren hezkuntzako 2., 3. eta 4. mailetan eskolatutako ikasle guztiena. Ikasleen jatorri sozioekonomikoa antzekoa zen; gehienak klase ertainekoak ziren.

Hautatutako ikastetxeak, testuan 1 Ikastetxea eta 2 Ikastetxea direnak, ikastolen sarekoak dira. Azken urteetan, sare horrek bigarren hezkuntzako 3. mailan Geografia eta 4. mailan Historia ingelesez irakasteko programa bat ezarri du. Datuak jaso genituenean, bi eskolak ingelesa irakats-hizkuntza den programa horretan parte hartzen ari ziren.

Emakumezko bi irakasleren - ikastetxe bakoitzean bat - eskoletan behaketak egiteko baimena jaso genuen. Bi irakasleek — testuan T1 eta T2 - esperientzia handia zuten irakaskuntzan. 1 Ikastetxeko T1 irakaslea 13 urtez baino gehiagoz izana zen irakasle, eta 2 Ikastetxeko T2 irakaslea, berriz, 18 urtez. Datuak bildu genituenean, bai T1 bai T2 Ingelesa irakasgai gisa ematen ari ziren, eta, gainera, Historia eta Geografia ingelesez. Bi irakasleek ingelesa irakats-hizkuntza (EMI) gisa irakasteko berariazko prestakuntza jasoa zuten ikastolen sarean bertan.

Ikasleei dagokienez, guztira 134 ziren: 80 ikasle 1 Ikastetxean eta 54 ikasle 2 Ikastetxean. Ikasle guztiak euskara-gaztelania elebidunak dira, hau da, bi hizkuntzok hitz egiteko gai dira. Jatorri linguistikoari dagokionez, ikasleen $\% 74,2 \mathrm{k}$ adierazi zuen bere ama-hizkuntza euskara dela, $\%$ 8,2k gaztelania dela, eta \% 18,7k bi hizkuntza horiek; gainerako \% 0,7a beste ama-hizkuntza bat duela adierazi zuen ikasle bati dagokio. Ikasleek adierazitakoaren arabera, \% 50ek astean 4 ordu baino gehiago ikasten zuten ingelesez (irakasgai gisa eta irakats-hizkuntza gisa), \% 19,8k 2-4 ordu, eta $\% 30,2 \mathrm{k} 2-3$ ordu.

\section{Tresnak eta prozedura}

Ikerketa honetan zenbait tresna eta teknika erabili ditugu datuak biltzeko. Alde batetik, bi irakasleei elkarrizketa erdiegituratu bat egin zitzaien atzerriko hizkuntzaren ikasgelako hizkuntza-erabilerari buruz, hala berena nola ikasleena. Bestetik, ikertzaile batek eta ikerketa-laguntzaile batek behaketak egin zituzten 19 eskola-saiotan, eta biek ohar etnografikoak hartu zituzten. Halaber, klaseen audioak grabatu ziren, geroago horiek transkribatu eta sakonago aztertu ahal izateko. Irakasleei egindako elkarrizketez eta oharrez gain, galde-sorta labur bat erabili zen ikasleei buruzko oinarrizko datuak biltzeko. Galde-sorta, besteak beste, item hauez osatuta zegoen: ikasleen hizkuntza-erabilera etxean, eskolan eta eskolatik kanpo, 
ikasleen gaitasuna hizkuntza-trebetasunetan euskaraz, gaztelaniaz eta ingelesez, eta haien adina eta generoa.

Elkarrizketak data-multzo handien analisi kualitatiboa egiteko Atlas.ti programarekin transkribatu eta aztertu ziren. Audio-grabazioak ere transkribatu eta aztertu ziren, kode-aldaketa gertatzen zen pasarteetan arreta jarrita, analisi kualitatiborako Atlas.ti eta kuantitatiborako SPSS programak erabiliz. Kode-aldaketako kasu guztiak zenbatu ziren, bai irakasleenak bai ikasleenak. Horri esker aztertu ahal izan genuen irakasleen kode-aldaketa ikasleenaren jarraipena zen edo tartean beste arrazoiren bat zegoen.

Galde-sortaren bidez lortutako informazioa SPSSn sartu zen analisi kuantitatiboak egiteko.

\section{EMAITZAK}

Atal honen hasieran, lehenengo ikerketa-galderari dagozkion emaitzak erakutsiko ditugu: Zer ezaugarri eta funtzio dituzte atzerriko hizkuntzaren ikasgelan izaten diren kode-aldaketek? Jarraian, bigarren ikerketa-galderari dagozkion emaitzak aurkeztuko ditugu: Irakasleek beren hizkuntzaerabileraz duten pertzepzioa bat al dator haien eskoletan behatutako hizkuntza-erabilerarekin?

\section{Kode-aldaketaren funtzioak}

Azpiatal honetan, gure ikerketan aurkitu ditugun kode-aldaketaren kategoriak eta funtzioak azalduko ditugu. Guztira, kode-aldaketako 267 kasu aurkitu genituen guk behatutako 19 eskola-saioetan. Emaitzak aurkezteko, beste zenbait egileren (Gierlinger 2015, Lo 2015, Littlewood \& Yu 2011, Lin 2006, Jones et al. 2013) funtzioen taxonomia oinarri hartuta taxutu dugun kode-aldaketaren kategorizazioa eta funtzioak erabiliko ditugu (1. taula), bai eta gure ikerketarako berariaz identifikatu ditugun beste kategoriak eta horien ezaugarriak ere (2. taula).

Analisi kualitatibo honetarako, gure ikerketan aurkitu ditugun kode-aldaketako kasu guztietatik hautaketa bat egin dugu, gure funtzioen kategorizazioen adibide adierazgarriak emate aldera. Pasarteak 1. taulako hurrenkerari jarraituz aurkeztuko ditugu.

Lehendabizi, (1) kategoria arautzailearen barruan, 'jokabideen/ikasgelaren kudeaketa' eta 'soziala eta afektiboa' azpikategoriei dagozkien kode-aldaketako kasuak aurkeztuko ditugu. Ondoren, (2) kategoria hezitzailearen barruan, 'lexikoaren transmisioa' eta 'edukiaren transmisioa' azpikategoriei dagozkien kode-aldaketako kasuak aurkeztuko ditugu. Kasu guztietan, kode-aldaketako adibidearen funtzioa azaldu ondoren, 'ekoizle', 'hizkuntza' eta 'mota' gisa identifikatu ditugun ezaugarriak ere azalduko ditugu. 


\section{Kode-aldaketa arautzailea}

Jarraian doazen bi adibideek erakusten dutenez, kode-aldaketa asmo arautzailez erabil daiteke:

1. pasartea

Kode-aldaketa arautzailea, ikasgela kudeatzeko funtzioaz

Ls1: S1-English3B-Obs1 ${ }^{2}$; (Irakasleak jarduera bat aurkezten du; hurrengo klasean egingo duten 'bingo' jokoa prestatzeko jarduera bat da) ${ }^{3}$.

T1: And how many bold words?

$\mathrm{S}^{4}$ : (kontatzen) one, two, three, four, five, six, seven!

T1: Seven! In bold means 'en negrita's. So you have to guess the meaning of the words that appear in this way, in bold.

1. pasartean, irakaslea asmo arautzailez aldatzen da hizkuntzaz. Kode-aldaketak ikasgela kudeatzeko funtzioa du, ikasleek beren jarraibide eta ekinbideak ulertuko dituztela ziurtatzeko. Irakaslea, jarraibideak ematean, ingelesetik gaztelaniara aldatzen da, hau da, haren eta ikasle gehienen H2ra. Irakasleak hizkuntza hori aukeratu bide zuen ikasleek eta berak gaztelania erabili ohi dutelako idatzizko testuetan ageri den terminologiaz ari direnean. Horrenbestez, irakasleak baliatu egiten du hiztun eleaniztunek hizkuntzen artean nabigatzeko duten gaitasuna, beren baitako errepertorio eleaniztuna unean uneko beharren arabera erabiliz. Irakaslea ingelesetik gaztelaniara aldatzen da, eta ostera ingelesera itzultzen da. Kode-aldaketa motari dagokionez, bistan da nahita egindakoa dela, esku artean duten jarduera ulertu eta egiteko funtsezkoa den hitz baten esanahia transmititzeko asmoz. Beraz, «bold» gako-hitza itzultzea erabakitzen du, letra lodiz zenbat hitz zeuden galdetzean ikasle askok zalantza egin zutela eta bakar batek erantzun zuela ikustean ohartu bide zelako askok ez zutela hitz horren esanahia ulertzen.

${ }^{2}$ Ls1 kodeak lehenengo saioa adierazten du. Saioak behaketaren hurrenkeraren arabera kodetu ziren. S1 lehenengo ikastetxea da (bi ziren). English3B kodeak B taldeko (maila bakoitzean bi talde daude, A eta B) 3. mailako ingeleseko eskola adierazten du. Obs1 kodeak adierazten du talde eta irakasgai horrekin egin genuen lehenengo behaketa zela.

3 Ikertzaileen oharrak eta azalpenak parentesi artean jaso dira.

${ }^{4} \mathrm{~S}$ kodeak ikaslea adierazten du.

5 Kode-aldaketako adibideak komatxo artean eta azpimarratuta ageri dira. 
2. pasartea

\section{Kode-aldaketa arautzailea, funtzio afektiboaz}

Ls1: S1-English3B-Obs1; (Irakaslea eta ikasleak etxerako lanak ikuskatzen ari dira, eta ikasle bat berandu sartu da gelara).

S: 'Barkatu, berandu etorri naiz'.

T1: 'Lasai!'

2. pasartea ere kode-aldaketaren beste adibide bat da. Baina, kasu honetan, funtzio afektiboa du, giro goxo eta atseginagoa sortzekoa. Berandu iritsi den ikasle batek gelan sartu eta barkamena eskatzen duenean, irakasleak euskaraz erantzuten dio. Ekoizlea irakaslea da, baina ikasleak erabili duen hizkuntzari (euskara) jarraipena ematen dio (mota). Irakasleak ingelesez erantzun zezakeen, ikasgelan ingelesa bakarrik erabiltzeko arauari eutsiz, baina ikaslearen $\mathrm{H} 1$ erabiltzea erabaki zuen ikaslearentzat segur aski deserosoa zen egoera arintzeko.

\section{Kode-aldaketa hezitzailea}

Hurrengo bi adibideek erakusten dute kode-aldaketa helburu hezitzailez erabil daitekeela.

\section{3. pasartea}

\section{Kode-aldaketa hezitzailea, lexikoa transmititzeko funtzioaz}

Ls12: S1-English2B-Obs2 ; (Konparazio bat idatzi aurretik, irakasleak ikasgela osoarekin batera aztertzen ditu konparazioak eta kontrasteak egiteko erabili diren esamoldeak).

T1: Can anybody tell me what it (whereas) means? Or what you think it can mean? (isilunea) It's for contrasting.

S1: (ulertezina)

T1: No? And if I put it this way? (arbelean esaldi bat idazten du) Whereas in the 1900 s...

S2: 'Nahiz eta'

T1: 'Nahiz eta'. 'Sin embargo, aunque' in Spanish. In Euskera? 'Hala eta guztiz ere nahiz eta'. So what are we going to do? We are going to put the translation. Let's write the translation in Euskera and in Spanish.

3. pasartean, kode-aldaketak kategoria hezitzailekoak dira nabarmen. Kasu honetan, lexikoaren transmisiorako erabiltzen dira. Irakasleak lehendabizi galdetzen du zer esan nahi duen «whereas» hitzak, eta adibide ba- 
tez laguntzen die ikasleei. Ikasle batek esanahi zuzena ematen du euskaraz (nahiz eta), eta ondoren irakasleak hitza euskaraz esaten du ostera eta gaztelaniazko itzulpena (sin embargo, aunque) eransten du. Beraz, lehendabizi ikasle bat da ekoizlea, irakaslearen eskaerari erantzuten dio, eta jarraian irakaslea da ekoizlea. Dagoeneko ikasi eta erabili dituzten esamoldeak berrikusten ari direnez, irakaslearen kode-aldaketa nahita egindakoa da, ikaslearen erantzuna berretsi nahi duelako. Segidan, euskarazko sinonimoak (hala eta guztiz ere) eta gaztelaniazkoak (aunque) gehitzen ditu, segur aski ikasleek hobeto uler dezaten esanahia bera eta nola erabil dezaketen «whereas» hitza esaldi batean.

4. pasartea

\section{Kode-aldaketa hezitzailea, edukia transmititzeko funtzioaz}

Ls7:S2-English3A-Obs1; (Irakasleak hitz berrien zerrenda bat idatzi du arbelean, ikasleek kopiatu ditzaten, hitzen ingelesezko definizioarekin batera; hitzetako bat «curfew»da, eta haren esanahia azaltzen hasten da).

T2: I think this word appears in text 7 (etena) it's the last word in text 7 (etena) ok. 'Curfew' is a word used more in conflicts, in conflicts' situation. If you find curfew in a country, it means that people cannot go out their houses at night. They might decide: 'there is a curfew at 10 o'clock at night'. This means that after 10 o'clock nobody can be out, if not you might be arrested. That is what curfew really means. And maybe there is somebody who can think of a translation in Basque or Spanish. (etena) So the translation can be?

S1: 'Toque de queda'.

T2: 'Toque de queda'. It probably doesn't mean anything to you, anyway.

$\mathrm{S} 2:$ 'de queda'?

S3: and in euskera?

T2: 'Toque de queda'. Do you have 'toque de queda' at home?

S3: and in euskera? (Irakasleak ez du entzun, eta inork ez du itzultzen)

4. pasartean ere kode-aldaketa hezitzailea da, eta edukia transmititzeko funtzioa du. Irakasleak «curfew» kontzeptu zaila azaltzen du eta itzultzeko eskatzen die ikasleei, ulertzen dutela ziurtatzeko. Kasu honetan, kode-aldaketaren ekoizlea ikasle bat da, eta erabiltzen duen hizkuntza gaztelania. Eskatutako kode-aldaketa da honako hau: irakasleak itzultzeko eskatzen die ikasleei, euskarara nahiz gaztelaniara. Beste ikasle batek kontzeptua euskarara itzultzeko eskatzen du, baina irakaslea ez da konturatzen eta beste ezein ikaslek ez du itzultzen.

Behaketen bidez ohartu ginen zenbait kasutan kode-aldaketa eskaera baten ondorio zela, batzuetan ikasleena eta beste batzuetan irakaslearena. Ikasleek itzulpena eskatzen zutenean, esanahia ulertzen ez zutelako izaten 
zen, eta irakasleek eskatzen zutenean, berriz, ikasleen ezagutza edo ulermena egiaztatzeko. Zenbaitetan, baina ez beti, eskaerarekin batera zehazten zen zer beste hizkuntza erabili behar zuten; gehienetan euskara izan ohi zen, ikastetxeko oinarrizko irakats-hizkuntza izaki. Bestalde, behaketen bidez ikusi dugu, gutxiagotan bada ere, irakasleak hala euskara nola gaztelania erabiltzen dituela esaldi berean, hurrengo pasartean bezala.

\section{5. pasartea \\ Kode-aldaketa hezitzailea bi hizkuntza gehituz, lexikoa transmititzeko funtzioaz}

Ls1: S1-English3B-Obs1; (Ikasleak 'bingo' jokoa berrikusteko lexikoa eta definizioak prestatzen ari dira).

S: What is 'earthquake' in Spanish?

T1: 'Terremoto' (etena) 'lurrikara'.

5. pasarteko kode-aldaketa ere hezitzailea da, eta lexikoa transmititzeko funtzioa du. Ikasleek berariaz eskatzen diote irakasleari gaztelaniara itzultzeko, eta irakasleak horixe egiten du, baina euskarazko itzulpena gehitzen du. Segur aski ikasleen euskarazko hitzaren ezagutza indartu nahi zuen irakasleak, ikasleen errepertorio eleaniztunean eta eskolako testuingurutik kanpo gaztelaniazko hitza mailegu gisa erabili ohi baita euskaraz lurrikarei buruz jardutean. Beste behin ikus daiteke irakasleak, ikasleen errepertorio eleaniztuna zabaltzea gain, euskara estandar formala sustatu nahi duela.

'Xede-hizkuntzaren erabilera pedagogikoa eteten' duen kode-aldaketa motari dagokionez, adibide bat aurkitu dugu, hurrengo pasartean ageri dena hain zuzen.

\section{6. pasartea}

\section{Xede-hizkuntzaren erabilera pedagogikoa eteten duen kode-aldaketa}

Ls16: S2-History4A-Obs2; (Erantzunei buruz eztabaidatzen ari dira, eta bati buruz hitz egiten ari direla, irakasleak bere iritzia ematen du).

T2: The country of the 'chapuza', everything is valid.

Irakasleak ekoizten duena gure eskeman xede-hizkuntzaren erabilera pedagogikoa eteten duen kode-aldaketa gisa identifikatu duguna da. Kasu honetan, kode-aldaketak ez du lexikoa transmititzeko funtzio hezitzailea, irakasleak ez baitu hitz edo kontzeptu zail baten esanahia ez itzultzen ez argitzen. Gaztelaniazko hitza (chapuza) bat-batean erabiltzen du, ez ja- 
rraipen moduan edo eskaera bati erantzunez. Hain zuzen ere, inplizituki mezu bat eransteko erabakitzen du hizkuntzaz aldatzea. Gaztelaniazko hitz hori gehituta, bere iritzia ematen du: «hori da herrialde horretaz pentsatzen dudana». Linek $(2013,7$. or.) «a radical break in the English pedagogic frame» gisa definitu du kode-aldaketako mota hau.

\section{Irakasleen pertzepzioa beren ikasgeletako hizkuntza-erabileraz}

Azpiatal honetan, irakasleek beren ikasgeletako hizkuntza-erabileraz eta kode-aldaketaz dituzten pertzepzioei buruzko emaitzak, elkarrizketen bidez bilduak, aurkeztuko ditugu.

Irakasleek elebakartasunean oinarritutako hizkuntzen bereizketaren irizpideari jarraituz erabiltzen dituzte hizkuntzak ikasgelan. Gure irakasleetako batek elkarrizketan ziurtatu zuen moduan: «Denboraren \% 99 ingelesez hitz egiten dut. Ehuneko ehun? Saiatzen naiz!». Ingeleseko irakasleek beren ikasgeletan xede-hizkuntza bakarrik erabili nahi dute, onartzen dute eta erabiltzea bultzatzen dute. Alabaina, zenbaitetan euskara eta gaztelania erabiltzen dituzte eta erabiltzea onartzen dute, normalean asmo jakin batekin, hala nola lexikoaren transmisioa (ikus 3. pasartea).

Behaketak egin genituen ikastoletako klaseen testuinguru eleaniztunean, irakasleek beste hizkuntza bat erabiltzea erabakitzen duten uneetan hizkuntza hori euskara, ikastetxeko H1, izaten da gehienetan, T1 irakasleak adierazi moduan: «Gaztelania erabiltzen dut hitzak sustraikideak direnean, bestela euskarara itzultzen ditut. Hobeto uler dezaten egiten dut». T1 eta T2 irakasleek gaztelaniazko hitz sustraikideen erabilera aipatzen dute, eta klaseen behaketan egiaztatu genuen ingelesezko zenbait hitz itzultzen zituztela gaztelaniazko hitz sustraikideak erabiliz.

Hizkuntzen bereizketa lortu nahi den testuinguru honetan interesgarria da T2 irakasleak esatea bere ikasleak eleaniztunak direla, eta eleaniztasuna balio erantsi bat dela. Ingelesezko irakasle soila baino gehiago zela ere adierazi zuen: «Hizkuntza-irakaslea naiz ni, ez ingeles hizkuntzako irakaslea. Euskaran ere lagundu badiezaieket, iruditzen zait ideia ona dela».

Irakasleek beren ikasleen hizkuntza-erabilerari buruz duten pertzepzioa ez dator bat klaseen behaketan ikusi genuenarekin; irakasleek elkarrizketetan adierazitakoaren arabera, ikasleek dezente erabiltzen dituzte $\mathrm{H} 1$ eta $\mathrm{H} 2$ ikasgelan. Normalean, irakasleek ez diete ikasleei hori egiten uzten, batez ere ikasgela osoa elkarrekin lanean ari denean, T1 irakaslearen esanetan «ingelesa erabiltzen duten toki bakarra delako» eta ahalik eta input gehien eman nahi dutelako. Alabaina, irakasleek diotenez, arau horrekin malguagoak dira ikasleak bikoteka edo talde txikietan ari direnean, eta beste bi hizkuntzak erabiltzen uzten diete ikasleei, T1 irakasleak adierazi moduan: «Uzten diet, baina beste hizkuntza batzuk erabiltzen dituztenean saiatzen naiz ingelesa erabiltzera animatzen». T2 irakasleak ere antzeko erantzuna 
eman zuen: «Printzipioz ez, baina nik erabiltzen dudan asmo bererako erabiltzen uzten diet; esaterako, zerbait argitzeko». Gure ikerketan ikusi genuen ikasleek euskara eta gaztelania erabiltzen dituztela talde txikietan lan egiten dutenean, baina oro har ez asko. Irakasleek irudipen hori izan lezakete ikasleek beti ingelesa bakarrik erabiltzea nahi dutelako.

Gure ikerketaren arabera, ikasgelan euskara eta gaztelania erabiltzen uzteari dagokionez kontraesana dago irakasleek esaten eta egiten dutenaren artean. Ikasleek beti ingelesa bakarrik erabiltzea nahi dutelarik, irakasleak nahiko zorrotzak dira ikasgela barruko hizkuntza-erabilerari dagokionez. Behaketetan agerian geratu zen bai T1 irakaslea bai T2 irakaslea nahiko zorrotzak direla ingelesa ez den beste hizkuntza batzuen erabilerarekiko. T1 eta T2 irakasleak sarritan ikusi genituen ikasleei ingelesa bakarrik erabili behar zutela gogorarazten. Hurrengo pasarteak horren adibide dira.

\section{7. pasartea}

\section{Xede-hizkuntza soilik erabiltzeko eskaera}

Ls4: S1-English3B-Obs2 ; ('Bingo' jokoaren entsegu batekin hasten da klasea. Irakasleak ikasleei gogorarazten die euskara edo gaztelania erabili gabe azaldu eta definitu behar dituztela hitzak).

T1: Now, student A will work with student B but you cannot use Basque and you cannot use Spanish. You have to be able to explain the meaning of these words in bold. Spanish and Basque forbidden! Translation forbidden!!

8. pasartea

\section{Xede-hizkuntza soilik erabiltzeko eskaera}

Ls16: S2-History4A-Obs2; (Ikasleak taldeka lan egiten hasten dira, eta euskara erabiltzen ari direla ohartzen denean, hots egiten du:)

T2: In English! (geroxeago, ikasle jakin bati berriro) In English!

7. eta 8. pasarteetan, T1 eta T2 irakasleek ikasleei gogorarazten diete ingelesa bakarrik erabili behar dutela, baita talde txikietan edo bikoteka lan egiten ari direnean ere. T1en arabera, «(ikasleak) ez ditugu zigortzen», baina 7. pasartean ikus dezakegu batzuetan behintzat nahiko gogor eskatzen duela ingelesa bakarrik erabiltzeko, beste bi hizkuntzen erabilera berariaz galaraziz. T2k gehitu zuenez, pizgarri moduan «badakite puntu bat gehiago ematen dudala ingelesa asko erabiltzeagatik». Beraz, ikasleek xede-hizkuntza bakarrik erabiltzeko estrategia gisa, irakasleek ingelesaren erabilera saritzen dute. 


\section{ONDORIOAK}

Ikerketa honen emaitzek erakusten dutenez, Euskal Herriko ikastetxeetan hizkuntzen bereizketa indar betean dagoen arren (Arocena, Cenoz \& Gorter, 2015), irakasle eta ikasleek kode-aldaketa erabiltzen dute egoera jakin batzuetan. Kode-aldaketa «arautzaile» edo «hezitzaile» kategorietan sailka daiteke. Gure behaketen arabera, kasu gehienetan asmo hezitzailez egiten da, hitz eta kontzeptu zail eta berrien ulermena errazteko. Gure behaketek berretsi egin zuten irakasleek elkarrizketetan emandako informazioa. Irakasleek beste hizkuntza batzuk nahita erabiltzen dituzte ikasleek ulertzen dutela egiaztatzeko. Sarritan, ikasle batek hizkuntzaz aldatzeko eskatzen duenean, hitz edo kontzeptu bat ezagutzen ez duelako izaten da.

Emaitza hauek erakusten dute, Gierlingerrek (2015) adierazitakoaren ildotik, kode-aldaketa pedagogikoa dela eta ez larrialdiko baliabide bat, eta, Lok (2015) ondorioztatu moduan, irakasleek edukiaren eta hizkuntzaren ikaskuntza bultzatzeko erabiltzen dutela ikasleen H1. Alde horretatik, gure emaitzek egiaztatzen dute irakasle eta ikasleek ez dutela beren $\mathrm{H} 1$ era zentzugabean erabiltzen, ez bada ikasteko eta helburu kognitiboengatik nahiz ikasleen beharrizanei erantzuteko. Batzuetan, beharrizan horiek afektiboak izaten dira, eta irakasleek haien $\mathrm{H} 1$ erabiliz erantzuten dute, normalean ikasleek erabilitako hizkuntzaren jarraipen gisa.

Littlewood eta Yuren (2011) arabera, kode-aldaketa ikaskuntzarako kaltegarria izan daiteke ikasleek beste hizkuntza batzuk ahal bezain laster erabiltzeko joera dutelako. Ikerketa honetan ez genuen joera hori antzeman 2., 3. eta 4. mailako ikasleengan. Horrenbestez, Lok (2014) ondorioztatutakoaren ildotik, H1en erabilerak behera egiten du ikasleek atzerriko hizkuntzan duten gaitasuna areagotu ahala.

Ikerketa honek erakusten du Euskal Herriko testuinguru eleaniztunean beste hizkuntza batzuk erabiltzen direla ingelesa atzerriko hizkuntza gisa irakasten den klaseetan, araua xede-hizkuntza soilik erabiltzea den arren. Ikerketa honetan parte hartu duten irakasleak ados badaude ere Cumminsek (2014) «monolingual instructional assumptions» deitutakoekin, arauarekiko desbideratzeak badaude: asmoa xede-hizkuntza soilik erabiltzea da, baina, praktikan, $\mathrm{H} 1$ eta $\mathrm{H} 2$ erabiltzen dituzte helburu jakin batekin; sarritan kontzeptu zailak ulertzen eta argitzen laguntzeko izaten da. Lasagabasterrek (2013) ondorio bera atera zuen Kolonbian CLIL irakasleekin egin zuen ikerketan. Beraz, kontraesana dago arauaren eta ikasgelan benetan gertatzen denaren artean. Irakasleak konturatzen dira kode-aldaketa erabiltzen dutela, baina zuhurtziaz hitz egiten dute jokabide horren norainokoaz. Linek (2006) azaldu moduan, uzkur ageri dira hizkuntzaz aldatzen direla onartzeko orduan. Izan ere, arauari eusten saiatzen dira jakitun direlako ikasgela dela ikasleek atzerriko hizkuntzarekiko hartu-emana duten leku bakarra, beste leku askotan gertatzen den moduan, hala nola Hong Kon- 
gen (Littlewood \& Yu, 2011). Bestalde, ondoriozta genezake irakasleak, esperientzia lagun, elebakartasunaren hesiak apurtzearen abantailez ohartzen hasiak direla, eta beraz atzerriko hizkuntzako saioetan $\mathrm{H} 1$ erabiltzea ez dela halabeharrezkoa, baizik eta aurrez pentsatutakoa ( $c f$. Gierlinger, 2015), H1 edo H2ren hizkuntza-maila hobetzeko.

Azterlan honen emaitzek agerian uzten dute ikerketa gehiago behar dela atzerriko hizkuntzaren irakaskuntzan planteamendu eleaniztunak baliatzearen inguruan. Horrez gain, beharrezkotzat jotzen dugu irakasleen prestakuntza-ikastaroetan aldaketak egitea elebakartasunean oinarritutako usteak eleaniztasunaren alde lerratzeko, ikaskuntza-baliabide guztiak erabili ahal izan ditzagun irakasleak kode-aldaketarekin deseroso sentitu beharrik gabe.

\title{
ESKER ONA
}

Lan honek MINECO/FEDERen [laguntza-zenbakia: EDU201563967-R] eta Eusko Jaurlaritzaren [laguntza-zenbakia: DREAM IT714-13] laguntza jaso du.

\begin{abstract}
This study addresses the presence and role of $L 1$ and $L 2$ in the L3 classroom in a time when code-switching is still viewed as detrimental for language acquisition. This study was carried out in the multilingual context of the Basque Country where beliefs on language separation are strongly rooted. Despite the growing number of studies emphasizing the potential that the systematic and functional use of $\mathrm{LI}$ in foreign language teaching might have, language education in multilingual settings is still ruled by the monolingual assumptions dominant for many years. Data for this study was collected through the medium of a week-long observation of English foreign language lessons and lessons through the medium of English (EMI) and also through interviews of the English language teachers. In addition, background information on students was collected through the means of questionnaires. The participants in this study were two secondary school teachers, from two different schools, and their 134 students. The analysis of the data shows that both teachers and students use the L1 and L2 in the L3 classroom to a certain extent and that it is for a purpose and with
\end{abstract}


a function. The results also show that teachers, through their experience, start seeing the pedagogical benefits of breaking the monolingual barriers.

Keywords: code-switching, multilingual education, multilingual practices, EMI, secondary education.

Este estudio se ocupa de la presencia y el papel de L1 y L2 en la clase L3 en un momento en que el cambio de código todavía se considera perjudicial para la adquisición del lenguaje. Este estudio se realizó en el contexto multilingüe del País Vasco, donde las creencias sobre la separación lingüística están fuertemente arraigadas. A pesar del creciente número de estudios que se centran en el potencial que podría tener el uso sistemático y funcional de LI en la enseñanza de lenguas extranjeras, la enseñanza de idiomas en contextos multilingües todavía se rige por supuestos monolingües dominantes. desde hace muchos años. Los datos de este estudio se recolectaron mediante la observación semanal de clases de inglés y lecciones a través del inglés y mediante entrevistas con profesores de inglés. Además, la información básica sobre los estudiantes se recopiló a través de cuestionarios. Los participantes en este estudio fueron dos profesores de secundaria de dos escuelas diferentes y sus 134 estudiantes. El análisis de los datos muestra que los docentes y los estudiantes usan el primer y segundo idioma en el aula de un tercer idioma hasta cierto punto y que es para un propósito y una función. Los resultados también muestran que los maestros, a través de su experiencia, están empezando a ver los beneficios educativos de romper las barreras monolingües.

Palabras clave: code-switching, educación multilingue, prácticas multilingues, EMI, educación secundaria.

Cette étude traite de la présence et du rôle de L1 et L2 dans la classe L3 dans un moment où la commutation de code est toujours considérée comme préjudiciable à l'acquisition de la langue. Cette étude a été réalisée dans le contexte multilingue du Pays Basque où les croyances sur la séparation linguistique sont fortement enracinées. Malgré le nombre croissant d'études mettant l'accent sur le potentiel que l'utilisation systématique et fonctionnelle de L1 dans l'enseignement des langues étrangères pourrait avoir, l'enseignement des langues dans des contextes multilingues est encore régi par les hypothèses monolingues dominantes depuis de nombreuses années. Les données de cette étude ont été recueillies au moyen d'une observation hebdomadaire de cours et de leçons de langue étrangère en anglais par le biais de l'anglais et par des entretiens avec des professeurs de langue anglaise. En outre, les informations de base sur les étudiants ont été recueillies au moyen de questionnaires. Les partici- 
pants à cette étude étaient deux enseignants du secondaire, issus de deux écoles différentes, et leurs 134 étudiants. L'analyse des données montre que les enseignants et les étudiants utilisent la première langue et la deuxième langue dans la classe de troisième langue dans une certaine mesure et que c'est dans un but et avec une fonction. Les résultats montrent également que les enseignants, grâce à leur expérience, commencent à voir les avantages pédagogiques de la rupture des barrières monolingues.

Mots-clé: code-switching, éducation multilingue, pratiques multilingues, EMI, education secondaire.

\section{ERREFERENTZIA BIBLIOGRAFIKOAK}

Arocena, E., Cenoz, J. \& Gorter, D. (2015). Teachers' beliefs in multilingual education in the Basque Country and in Friesland. Journal of Immersion and Content-Based Language Education, 3:2, 169-193. DOI 10.1075/jicb.3.2.01aro

Arocena, E., \& Popma, J. (2014). English language teaching in secondary education and the use of English outside school; a comparison of the Basque Country and Friesland. Leeuwarden/Ljouwert: Mercator European Research Centre on Multilingualism and Language Learning.

Arocena, E. (2017). Multilingual Education; Teachers' Beliefs and Language Use in the Classroom. Doktore-tesi argitaragabea. Euskal Herriko Unibertsitatea, UPV/EHU.

Ballinger, S. (2015). Linking content, linking students: a cross-linguistic pedagogical intervention. In J. Cenoz and D. Gorter (Eds.), Multilingual Education; Between language learning and translanguaging (35.-60. or.). Cambridge, United Kingdom: Cambridge University Press

Costa, F. (2011). Code-Switching in CLIL Contexts. In C.E. Urmeneta, N. Evnitskaya, E. Moore, \& A. Patino (Eds.), AICLE CLIL EMILE: Educación Plurilingüe: Experiencias, Research \& Politiques (15.-27. or.). Barcelona: Servei de Publicacions de la Universitat Autónoma de Barcelona.

Cummins, J. (2014). Rethinking pedagogical assumptions in Canadian French immersion programs. Journal of Immersion and Content-Based Language Education, 2(1), 3-22. doi: 10.1075/jicb.2.1.01cum

Ghorbani, A. (2011). First language use in the context of Iranian EFL classroom discourse (Unpublished doctoral dissertation). University of Malaya, Malaysia. Retrieved from http://studentsrepo.um.edu.my/5733/1/Amirabbas_ Ghorbani.pdf

Gierlinger, E. (2015). 'You can speak German, sir': on the complexity of teachers' L1 use in CLIL, Language and Education, DOI: $10.1080 / 09500782.2015 .1023733$

Lasagabaster, D. (2013). The use of the L1 in CLIL classes: The teachers' perspective. Latin American Journal of Content and Language Integrated Learning, 6(2), 1-21. DOI: 10.5294/laclil.2013.6.2.1 eISSN 2322-9721. 
Levine, G. S. (2011). Code choice in the language classroom. Bristol: Multilingual Matters.

Lewis, G., Jones, B. \& Baker, C. (2013). 100 Bilingual Lessons: Distributing Two Languages in Classrooms. In C. Abello-Contesse, P. M. Chandler, M. D. López-Jiménez and R. Chacón-Beltrán (Eds.), Bilingual and Multilingual Education in the 21 $1^{\text {st }}$ Century (107.-135. or.). Bristol, England: Multilingual Matters.

Lin, A. (2006). Beyond Linguistic Purism in Language-in-education Policy and Practice: Exploring Bilingual Pedagogies in a Hong Kong Science Classroom, Language and Education, 20(4), 287-305

Lin, A. (2013). Classroom code-switching: Three decades of research. Applied Linguistics Review, 4(1), 195-218.

Lin, A. (2015). Conceptualising the potential role of L1 in CLIL. Language, Culture and Curriculum, 28(1), 74-89. doi: 10.1080/07908318.2014.1000926

Littlewood, W., \& Yu, B. (2011). First language and target language in the foreign language classroom. Language Teaching, 44 (1), 64-77. DOI: 10.1017/ S0261444809990310

Lo, Y. Y. (2015). How much L1 is too much? Teachers' language use in response to students' abilities and classroom interaction in Content and Language Integrated Learning. International Journal of Bilingual Education and Bilingualism, 18(3), 270-288. doi: 10.1080/13670050.2014.988112

Loewen, S. (2014). Introduction to instructive second language acquisition. New York: Routledge.

Macaro, E. (2005). Codeswitching in the L2 Classroom: A Communication and Learning Strategy. In E. Llurda (Ed.), Non-native Language Teachers: Perceptions, Challenges and Contributions to the Profession, (63.-84. or.). New York: Springer.

Macaro, E. (2009). Teacher use of codeswitching in the second language classroom: Exploring 'optimal' use. In M. Turnbull \& J. Dailey-O'Cain (Eds.), First language use in second and foreign language learning (35.-49. or.). Clevedon: Multilingual Matters.

McMillan, B., \& Turnbull, M. (2009). Teachers' use of the first language in French immersion: Revisiting a core principle. In B. McMillan \& M. Turnbull (Eds.), First language use in second and foreign language learning (15.-34. or.). Bristol: Multilingual Matters.

Poplack, S. (2001). Code-switching (linguistic). In N. Smelser \& P. Baltes (Eds.), International encyclopedia of the social and behavioural sciences, 2062-2065.

Storch, N., \& Aldosari, A. (2010). Learners' use of first language (Arabic) in pair work in an EFL class. Language Teaching Research, 14(4), 355-375. doi: $10.1177 / 1362168810375362$

Swain, M. \& Lapkin, S. (2000). Task-based second language learning: the uses of the first language. Language Teaching Research, 4 (3), 251-274. doi: $10.1177 / 136216880000400304$ 